\title{
Effect of pasture and intensive feeding systems on the carcass and meat quality of buffalo
}

\author{
Michela Contò $^{1, *}$, Giulia Francesca Cifuni ${ }^{1}$, Miriam lacurto ${ }^{1}$, and Sebastiana Failla ${ }^{1}$
}

\author{
* Corresponding Author: Michela Contò \\ Tel: +39-0690090231 \\ E-mail: michela.conto@crea.gov.it \\ ${ }^{1}$ Consiglio per la Ricerca in Agricoltura e \\ I'Analisi dell'Economia Agraria (CREA), \\ Centro di ricerca Zootecnia e Acquacoltura \\ (Research Centre for Animal Production and \\ Aquaculture), Via Salaria 31, Monterotondo, \\ Rome 00016, Italy \\ ORCID \\ Michela Contò \\ https://orcid.org/0000-0002-8244-1699 \\ Giulia Francesca Cifuni \\ https://orcid.org/0000-0002-4558-3145 \\ Miriam lacurto \\ https://orcid.org/0000-0002-8361-3210 \\ Sebastiana Failla \\ https://orcid.org/0000-0003-0901-0910
}

Submitted Mar 25, 2021; Revised Apr 12, 2021; Accepted Apr 28, 2021
Objective: This work was carried out to evaluate the effect of pasture (PA) feeding on buffalo meat quality compared with buffaloes reared intensively with the use of corn silage as a forage base or alternatively with polyphite meadow hay $(\mathrm{PH})$.

Methods: Thirty Mediterranean bull buffaloes were distributed into three experimental diet groups: maize silage (MS), $\mathrm{PH}$, and PA. The animals were slaughtered at a live weight of $250 \mathrm{~kg}$, and carcass and meat quality were evaluated. After 7 days of ageing, physical and chemical parameters of longissimus thoracis muscle were determined. To evaluate lipid oxidation the thiobarbituric acid reactive substances was tested at 7 and 14 days, and also the fatty acid profile was recorded by gas chromatography.

Results: The PA group, even if it showed carcass parameters lower than those of the silage maize group, reported a good meat percentage ( $60.59 \%$ vs $58.46 \%$, respectively) and lower fat percentage $(\mathrm{p}<0.001)$. PA-fed animals showed meat redness, and even if only on raw meat, shear force was higher than the others. Low values of conjugate linoleic acid, polyunsaturated fatty acids, and n-3 were reported in the silage maize group. Principal component analysis (PCA) clearly showed the influence of different diets on meat quality, and PCA1 and PCA2 explained $82 \%$ of the variability.

Conclusion: Buffaloes reared on PA had meat with high nutritional value even if they showed poor carcass performance compared to the animals fed on MS. Buffaloes fed on polyphite hay were in an intermediate position, similar to grazing animals, according to the same nutritional determinations.

Keywords: Buffalo; Feeding System; Grazing; Meat Quality

\section{INTRODUCTION}

Italy, among Western countries, has more buffalo heads; in 2019, the buffalo population was estimated to be 402,290 heads. The principal Italian buffalo product is "Mozzarella di Bufala DOP", but in the last decade, buffalo meat has also increased by $16 \%$ (FAOStat data 2019). This trend is due to high meat nutritional values, such as low cholesterol levels, high iron content, and low fat content é [1-4] and because buffalo meat is comparable to beef in many of its physicochemical, nutritional and functional properties and sensory attributes $[5,6]$.

Buffaloes are usually bred in South Italy in intensive systems for mozzarella cheese production [7], where, except for the summer season, there are pastures (PA) that could be used for semi-extensive breeding of buffalo males, leading to increased producer income thanks to lower production costs due to the rusticity of the species, which shows good digestive capacity for roughage [8].

In order to meet market demands and breed high-quality standard animals, several studies showed the influence of feeding on carcass quality and meat characteristics [8]. 
More recently, it has been demonstrated that using adequate feeding strategies for fattening buffaloes favourable nutritional characteristics can be achieved [8].

Studies to improve the performance and carcass quality of buffaloes [9] noticed that the supplementation of PA with concentrate enhances the growth and carcass characteristics, whereas animals grazing only PA had a more favourable fatty acid profile.

Previous our research [1] has shown that the type of finishing diet (hay or maize silage [MS]) for fattening buffaloes has a significant effect on carcass characteristics and meat quality. Finishing on MS produces carcasses with higher fat deposition and meat with a less favourable fatty acid profile (i.e. a lower $\mathrm{P} / \mathrm{S}$ ratio and $\alpha$-linolenic fatty acid content) in relation to human health. Moreover, PA-raised animals are lower in overall intramuscular fat, and it would seem that grass-fed animals could have lower cholesterol content and higher concentrations of antioxidant molecules, precursors of vitamins, minerals, n-3 fatty acids and increased trans vaccenic acid, used for the de novo synthesis of conjugate linoleic acid (CLA) [10]. Also, the meat of grass-fed beef cows could be darker than that of cows fed on concentrate [11].

Consumers' interest is focused on environmental sustainability, animal welfare and the nutritional values of animal products, and though this order changes according to the level of education, lifestyle choices and customs with a marked temporal effect, consumer behaviour is generally linked to healthy choices [12]. In particular, for meat products, the system of raising can inform these interests, while also improving the nutritional value of meat; indeed, forage or grassfeeding can modify the fatty acid composition and antioxidant content to improve nutritional, organoleptic and colour stability $[13,14]$.

The aim of this work was to evaluate the effects of PA feeding on the carcass composition and physical-chemical and nutritional qualities of buffalo meat, in comparison with buffaloes reared intensively with the use of corn silage as a forage base or alternatively with polyphite meadow hay.

\section{MATERIALS AND METHODS}

\section{Animals and diets}

The experiment was carried out at the Research Centre for Animal Production and Aquaculture (CREA-ZA) in Central Italy, and the experiment was conducted for approximately 6 months from January to June. Thirty Italian Mediterranean buffalo bulls, after weaning (approximately 3 months), were reared together until 5 months of age on multiple boxes. After that, they were randomly distributed into three experimental diet groups: 10 animals were fed on MS ad libitum; 10 animals were fed on polyphite meadow hay (PH) ad libitum; and 10 animals were fed on PA. All animals received a supplement of maize grain $(0.8 \mathrm{~kg} / \mathrm{d}$ per $100 \mathrm{~kg}$ live weight $)$ and protein concentrate (500 g head), and they had free access to water. The MS and PH groups were kept in a box with free access to a paddock, while the PA group was reared in grazed meadows with Gramineae as the principal component.

To determine the chemical composition of the diets (Table 1), a sample of MS and hay was taken monthly for the experimental period, while the PA sample was taken monthly from three boxes to prevent access by the animals, as reported by Fruet et al [15]. A single sample for maize grain and protein concentrate was taken for the total experimental period.

Each sample of MA, hay, and PA was combined to form a single sample that was suitably mixed. Maize grain and protein concentrate were dried in a forced-air oven at $65^{\circ} \mathrm{C}$ for 72 hours and then ground to a mesh size of $1 \mathrm{~mm}$. Analysis of the dry matter (DM), crude protein, and ether extract (EE) from the diets was conducted according to the AOAC

Table 1. Chemical composition of feedstuffs

\begin{tabular}{|c|c|c|c|c|c|}
\hline Item & MS & $\mathrm{PH}$ & PA & Maize grain & Protein concentrate \\
\hline Dry matter (\%) & 34.5 & 86.9 & 36.6 & 88.1 & 87 \\
\hline Crude protein (\%) & 2.7 & 11.0 & 3.5 & 9.0 & 38 \\
\hline Ether extract (\%) & 1.1 & 1.6 & 1.1 & 3.5 & 3.5 \\
\hline Ash (\%) & 1.6 & 5.7 & 2.9 & 1.6 & 9.5 \\
\hline $\mathrm{N}$-free extract (\%) & 21.6 & 44.1 & 17.6 & 71.4 & 25 \\
\hline Crude fibre (\%) & 6.5 & 23.4 & 12.5 & 2.6 & 12 \\
\hline $\operatorname{NDF}(\%)$ & 15.7 & 51.5 & 22.9 & 8.9 & 20.4 \\
\hline ADF $(\%)$ & 9.0 & 28.8 & 14.1 & 3.2 & 9.5 \\
\hline C16:0 & 17.1 & 24.4 & 19.3 & 11.5 & 14.1 \\
\hline C18:0 & 3.5 & 5.8 & 4.2 & 1.8 & 3.8 \\
\hline C18:1cis-9 & 25.3 & 20.6 & 11.4 & 25.7 & 24.3 \\
\hline C18:2 n-6 & 46.2 & 28.3 & 22.5 & 55.9 & 49.6 \\
\hline C18:3 n-3 & 4.7 & 18.2 & 39.4 & 2.3 & 5.8 \\
\hline
\end{tabular}

MS, maize silage; $\mathrm{PH}$, polyphite meadow hay; PA, pastures; NDF, neutral detergent fiber; ADF, acid detergent fiber. 
[16]. The concentrations of neutral detergent fibre and acid detergent fibre were analysed according to the method described by Van Soest et al [17]. The principal fatty acids were determined with the same method reported later for meat.

Carcass parameters and physical analyses

At approximately $250 \mathrm{~kg}$ of live weight the animals were slaughtered by captive bolt pistol and exsanguination in experimental slaughterhouses. After slaughter and removal of the head, skin and feet, the digestive tract and rumen were removed and weighed before and after emptying. Carcasses were split into two sides and chilled at $2^{\circ} \mathrm{C} \pm 1^{\circ} \mathrm{C}$; after 7 days of ageing, the carcass sides were evaluated through visual assessment by a trained and experienced evaluator for conformation and fatness according to the EU standard method SEUROP classification [18]. Each class of both scales (conformation and fatness) was subdivided into 3 subclasses, obtaining 18 subclasses for conformation and 15 for fatness evaluation.

From the right half carcass, 11 anatomical regions were dissected, 7 from the hindquarter (neck, fore shin, shoulder, brisket 1-6, brisket 7-13, flat ribs 1-6, plate ribs 7-13) and 4 from the forequarter (loin, distal pelvic limb, proximal pelvic limb and abdominal region), as reported in Figure 1. Carcasses and all regions considered were weighed and dissected for meat bones and fat percentage determination.

After 7 days of ageing, the longissimus thoracis muscle (LT), between 7th to 11th thoracic ribs, was taken from each half carcass and divided into two portions. The portions were, also, divided in three $2.5 \mathrm{~cm}$ steak slices and two of them used to perform physical and chemical analysis at 7 days, and the other portion was stored in a polyethylene bag under vacuum at $4^{\circ} \mathrm{C}$ until 14 days of ageing to determine oxidative processes. The chemicals analyses were performed in duplicate and the means were used for statistical data analysis.

Muscle $\mathrm{pH}$ was measured with a portable Hanna $\mathrm{pH}$ metre with an Inlab 427 probe, with temperature compensation performed by making a scalpel incision in the muscle, and water-holding capacity (WHC), measured as water loss in raw and cooked meat $(\mathrm{CL})$, was determined according to Honikel [19]. Cooked samples were obtained cooked a slices in a plastic bag in water bath at $80^{\circ} \mathrm{C}$ until a $75^{\circ} \mathrm{C}$ at core and cooled for $45 \mathrm{~min}$ in running water. The shear force on raw and cooked meat was evaluated using an Instron 5543 equipped with a Warner-Bratzler shear force device (WBS) as described in detail by Christensen et al [20], applied on six sample blocks $2 \times 1 \times 1 \mathrm{~cm}$ cross section and cut perpendicularly of the fibres direction. For cooked samples the same procedure described above was used and the means were used to statical analysis.

Meat colour was evaluated using the CIELAB system to estimate $\mathrm{L}^{*}, \mathrm{a}^{*}$, and $\mathrm{b}^{\star}$ (lightness, redness, and yellowness,

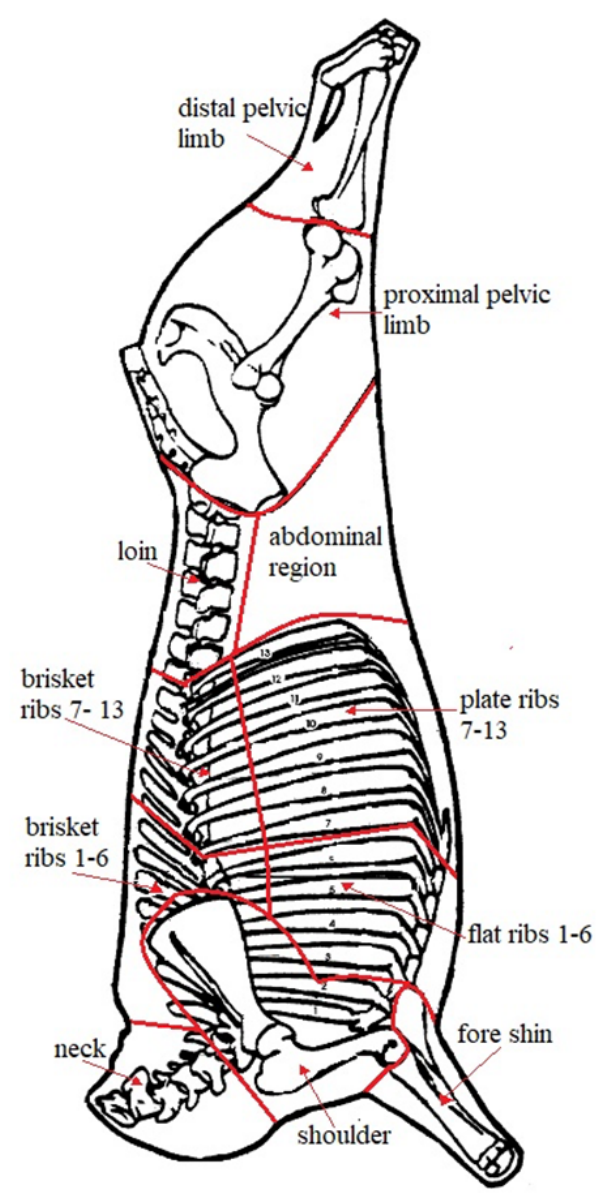

Figure 1. Carcass subdivision into 11 anatomical regions, from the right half carcass, neck, fore shin, shoulder, brisket 1-6, brisket 7-13, flat ribs 1-6, plate ribs 7-13, loin, distal pelvic limb, proximal pelvic limb and abdominal region.

respectively) and calculate $\Delta \mathrm{E}^{\star}$ with a Minolta CM-2006, as reported in detail by Ripoll et al [21]. For each sample six determination was performed and the means were used for statistical data analysis.

\section{Chemical analyses}

Chemical composition, DM, ash, EE and protein of the diets and meat at 7 days of ageing were determined by AOAC [16].

Total and insoluble collagen content was determined according to Christensen et al [20] by quantification of hydroxyproline. For total collagen $5 \mathrm{~g}$ of chopped meat samples were hydrolyzed in $30 \mathrm{~mL}$ of $6 \mathrm{M} \mathrm{HCl}$ at $110^{\circ} \mathrm{C}$ overnight; instead for insoluble collagen, before hydrolyzing process, samples were cooked for $2 \mathrm{~h}$ at $90^{\circ} \mathrm{C}$ in $20 \mathrm{~mL}$ of $0.9 \% \mathrm{NaCl}$ solution, after cooled samples were centrifuge and the suspension in aqueous phase was collected by filtrating and add to the pellet. Pellet and filter was hydrolyzed as reported above. After hydrolyzing process samples were neutralized at $7 \mathrm{pH}$, an aliquot was incubated at room temperature for 20 min with the oxidative solution of Chloramina-T, later 
the same aliquot was incubated at $60^{\circ} \mathrm{C}$ per $15 \mathrm{~min}$ with colorimetric solution, after cooled in ice bath, samples were read at $560 \mathrm{~nm}$. Total and insoluble collagen were calculated by standard curve of hydroxyproline standard for conversion factor 8 .

Lipid oxidation was analysing at 7 and 14 days after slaughter by thiobarbituric acid reactive substances assay (TBARS), that measuring the level of malondialdehyde (MDA), a principal lipid oxidation product, following the procedure reported by Bergamo et al [22]. Meat samples were homogenized in water, and after proteins were precipitated with trichloroacetic acid (TCA 10\%), the deproteinized sample was incubated with thiobarbituric acid at $90^{\circ} \mathrm{C}$ for $30 \mathrm{~min}$ and subsequently detected by HPLC. An aliquot, $20 \mu \mathrm{L}$, of sample was inject into $\mathrm{C} 18$ reverse phase column $(4.6 \times 250 \mathrm{~mm} 5 \mu \mathrm{m})$ with isocratic mobile phase of Buffer phosphate $5 \mathrm{mM} \mathrm{pH}$ 7:Acetonitril $85: 15$ (v:v) and read by fluorescence, $\lambda \mathrm{EX}=515 \mathrm{~nm} ; \Lambda \mathrm{em}=$ $543 \mathrm{~nm}$. The MDA peak was identified by the elution profile of authentic standard. A calibration curve was performed using 1,1,3,3-tetraethoxypropane (TEP) solutions of concentrations varying from 0.007 to $1.25 \mathrm{mg} / \mathrm{mL}$. The TBARS concentration was expressed as $\mathrm{mg}$ of $\mathrm{MDA} / \mathrm{kg}$ of meat and triplicate analyses were performed for all samples. The limit of detection (LOD) and limit of quantitation (LOQ) were found to be 0.00042 and $0.0014 \mathrm{mg} / \mathrm{mL}$, respectively.

Fatty acids were extracted by chloroform:methanol (2:1 $\mathrm{v} / \mathrm{v})$, before to perform the fats extraction C19:0 fatty acid was added as to internal standard on samples. Fat was methylated with methanolic $\mathrm{KOH}$, and methyl esters were injected in a gas chromatography flame ionization detector with a fused silica capillary column coated with $100 \%$ cyanopropyl polysiloxane as described in detail in Cifuni et al [1]. Peak identification was performed by comparing the sample peaks with Supelco37 (Merck-Sigma Aldrich, Bellefonte, PA, USA) standard peaks, expressed as the percentage of total fatty acid methyl ester. The amounts of saturated fatty acids (SFA), monounsaturated fatty acids (MUFA), polyunsaturated fatty acids (PUFA), n-6/n-3 PUFA ratio, PUFA/SFA ratio, thrombogenic index (TI) and atherogenic index as reported in Ulbricht et al [23] were calculated.

\section{Statistical analysis}

All data were subjected to analysis of variance with a mono factorial model, using procedure general linear model of SAS (SAS Inst. Inc., Cary, NC, USA), and the level of significance between the groups was determined according to Tukey's test using $\mathrm{p}<0.05$ as the limit to identify significant differences. In addition, principal component analysis (PCA) was performed by SAS to identify the components that absorb greater variability and was able to separate the three feeding systems. For this analysis, only the qualitative parameters of meat that showed significant differences between experimental groups were used.

\section{RESULTS}

\section{Slaughter performance}

The PA group reached the final weight at the highest slaughter age (+48 days compared to the mean of the other groups $\mathrm{p}<0.001)$ and consequently a lower $(\mathrm{p}=0.015)$ daily gain (ADG), also showing the highest gastro enteric content (43.0 vs $21.6 \mathrm{~kg}$ of the MS group), with consequent minor net live weight; however, the carcass weight of these animals was not significantly different from the $\mathrm{PH}$ group, although the weight was $-28 \mathrm{~kg}$ lower than the MS group (Table 2).

Animals fed MS significantly differed from the PA group

Table 2. Slaughter and carcass performances

\begin{tabular}{|c|c|c|c|c|c|}
\hline Items & MS & $\mathrm{PH}$ & PA & RMSE & p-value \\
\hline Live weight (kg) & 256.6 & 256.0 & 255.9 & 16.63 & 0.995 \\
\hline Slaughter age (d) & $331^{\mathrm{b}}$ & $341^{b}$ & $384^{a}$ & 11.70 & $<0.001$ \\
\hline GEC (kg) & $21.6^{c}$ & $39.6^{b}$ & $43.0^{\mathrm{a}}$ & 5.20 & $<0.001$ \\
\hline $\operatorname{ADG}(\mathrm{kg} / \mathrm{d})$ & $0.65^{\mathrm{a}}$ & $0.63^{\mathrm{a}}$ & $0.58^{b}$ & 0.05 & 0.015 \\
\hline NLW $(\mathrm{kg})$ & $235.0^{a}$ & $216.5^{\mathrm{b}}$ & $212.9^{b}$ & 16.30 & 0.011 \\
\hline Carcass weight (kg) & $133.6^{\mathrm{a}}$ & $118.7^{\mathrm{b}}$ & $105.2^{b}$ & 10.73 & $<0.001$ \\
\hline Dressing \% & $56.9^{a}$ & $54.7^{\mathrm{ab}}$ & $49.5^{b}$ & 2.32 & $<0.001$ \\
\hline Conformation point ${ }^{1)}$ & $6.33^{\mathrm{a}}$ & $6.35^{\mathrm{a}}$ & $5.26^{b}$ & 0.47 & $<0.001$ \\
\hline Fat point ${ }^{1)}$ & $5.73^{\mathrm{a}}$ & $3.54^{b}$ & $3.08^{b}$ & 0.74 & $<0.001$ \\
\hline Meat $(\%)^{2)}$ & $58.46^{b}$ & $62.09^{a}$ & $60.61^{a}$ & 1.97 & $<0.001$ \\
\hline Bone $(\%)^{2)}$ & $23.04^{b}$ & $24.37^{b}$ & $26.44^{a}$ & 1.51 & 0.012 \\
\hline Total fat $(\%)^{2)}$ & $14.45^{\mathrm{a}}$ & $9.25^{b}$ & $8.60^{b}$ & 0.91 & $<0.001$ \\
\hline
\end{tabular}

MS, maize silage; PH, polyphite meadow hay; PA, pastures; RMSE, root mean standard error; GEC, gastro enteric contents; ADG, average daily gain; NLW, net live weight; Total fat, subcutaneous and intermuscular fat.

1) SEUROP classification.

2) Percentage on entire carcass (the complement to 100 is given by the other tissues).

${ }^{a-c}$ Means within a row without a common superscript letter differ $(p<0.05)$. 
in dressing percentage ( $56.9 \%$ vs $49.5 \% \mathrm{p}<0.001$ ). The conformation score was similar for MS and $\mathrm{PH}$, both differing by PA ( $<<0.001)$, while the PA and PH groups showed the leanest carcasses according to the fatness score. This result was comparable to the carcass tissue percentage, where MS carcasses showed a fat percentage greater than $+5 \%$; conversely, the $\mathrm{PH}$ and $\mathrm{PA}$ groups had significantly higher meat percentages $(62.09 \%$ and $60.61 \%$, respectively, compared to $58.46 \%$ of the MS group). For bone percentage, the MS and $\mathrm{PA}$ showed opposite trends, with $\mathrm{PH}$ in the middle position.

\section{Anatomical regions}

The percentage of anatomical regions (Table 3 ) showed a few significant differences. The proximate pelvic limb $(27.7 \%$ on the average) and shoulder ( $12.60 \%$ on the average), on the hindquarter, were the most representative regions of the carcass. The regions where subcutaneous fat was usually stored had a higher incidence in MS carcasses, as did the abdominal region (4.03\% vs $3.72 \%$ means of $\mathrm{PH}$ and $\mathrm{PA}$ ), while the distal pelvic limb reported the opposite trend $(\mathrm{p}<0.001)$. The other anatomical regions did not show significant differences.

\section{Physical and chemical quality}

Regarding physical analysis (Table 4), $\mathrm{pH}$ was higher for the PA group ( $\mathrm{p}<0.001$ ), while MS showed a lower value ( 5.73 vs 5.54 , respectively). No difference was found in WHC \%; instead, cooking loss reported a higher value for the MS group than for the $\mathrm{PH}$ group $(\mathrm{p}<0.001)$.

Table 3. Comparison of anatomical regions

\begin{tabular}{lccccc}
\hline Parameters (\%) & MS & PH & PA & RSME & p-value \\
\hline Distal pelvic limb & $7.19^{\mathrm{b}}$ & $7.96^{\mathrm{a}}$ & $8.24^{\mathrm{a}}$ & 0.43 & $<0.001$ \\
Proximal pelvic limb & 27.66 & 27.81 & 27.53 & 0.75 & 0.692 \\
Loin & 6.63 & 6.61 & 6.53 & 0.38 & 0.806 \\
Abdominal region & $4.68^{\mathrm{a}}$ & $4.03^{\mathrm{b}}$ & $3.72^{\mathrm{b}}$ & 0.28 & 0.48 \\
Plate ribs 7-13 & 7.15 & 6.95 & 6.75 & 0.66 & 0.001 \\
Brisket 7-13 rib & 6.01 & 5.82 & 5.96 & 0.55 & 0.701 \\
Flat ribs 1-6 & 9.21 & 8.72 & 8.91 & 0.36 & 0.147 \\
Brisket 1-6 & 6.39 & 6.46 & 6.61 & 0.61 & 0.375 \\
Shoulder & 12.45 & 12.62 & 12.74 & 0.52 & 0.586 \\
Neck & 8.51 & 8.62 & 8.69 & 0.18 & 0.731 \\
Fore shin & $4.12^{\mathrm{b}}$ & $4.40^{\mathrm{a}}$ & $4.32^{\mathrm{a}}$ & & 0.006 \\
\hline
\end{tabular}

MS, maize silage; $\mathrm{PH}$, polyphite meadow hay; PA, pastures; RMSE, root mean standard error.

a,b Means within a row without a common superscript letter differ $(p<0.05)$.

Table 4. Physical and chemical parameters of longissimus thoracis muscle

\begin{tabular}{|c|c|c|c|c|c|}
\hline Parameters & MS & PH & PA & RMSE & p-value \\
\hline $\mathrm{pH}$ & $5.54^{\mathrm{c}}$ & $5.62^{b}$ & $5.73^{\mathrm{a}}$ & 0.08 & $<0.001$ \\
\hline WHC (\%) & 1.16 & 1.03 & 1.20 & 0.28 & 0.415 \\
\hline Cooking loss (\%) & $30.55^{\mathrm{a}}$ & $27.41^{\mathrm{b}}$ & $28.88^{\mathrm{ab}}$ & 1.65 & $<0.001$ \\
\hline$L^{*}$ & $46.81^{a}$ & $42.46^{\mathrm{b}}$ & $41.10^{b}$ & 1.80 & $<0.001$ \\
\hline$a^{*}$ & $18.10^{b}$ & $19.65^{\mathrm{a}}$ & $19.92^{\mathrm{a}}$ & 1.16 & 0.003 \\
\hline$b^{*}$ & $14.53^{\mathrm{a}}$ & $12.60^{b}$ & $10.93^{b}$ & 1.12 & $<0.001$ \\
\hline WBS raw $(\mathrm{N})$ & $50.73^{\mathrm{b}}$ & $58.81^{a}$ & $60.20^{a}$ & 6.79 & 0.013 \\
\hline WBS cooked (N) & 47.197 & 44.34 & 46.01 & 9.91 & 0.827 \\
\hline Dry matter (\%) & 22.66 & 23.41 & 23.06 & 0.97 & 0.125 \\
\hline Ash (\%) & 1.05 & 1.06 & 1.14 & 0.11 & 0.082 \\
\hline Ether extract (\%) & $1.18^{\mathrm{a}}$ & $1.17^{\mathrm{a}}$ & $0.67^{b}$ & 0.26 & $<0.001$ \\
\hline Crude protein (\%) & 20.43 & 21.16 & 21.25 & 0.85 & 0.094 \\
\hline Total collagen $(\mathrm{mg} / \mathrm{g})$ & $3.05^{b}$ & $3.80^{a}$ & $4.30^{\mathrm{a}}$ & 0.59 & 0.004 \\
\hline Insoluble collagen $(\mathrm{mg} / \mathrm{g})$ & 2.17 & 2.36 & 2.49 & 0.44 & 0.309 \\
\hline TBARS 7 d (mg MDA/kg) & $0.16^{\mathrm{a}}$ & $0.14^{\mathrm{ab}}$ & $0.11^{b}$ & 0.04 & 0.033 \\
\hline TBARS 14 d (mg MDA/kg) & $0.23^{\mathrm{a}}$ & $0.15^{b}$ & $0.14^{b}$ & 0.04 & $<0.001$ \\
\hline
\end{tabular}

MS, maize silage; PH, polyphite meadow hay; PA, pastures; RMSE, root mean standard error; WHC, water-holding capacity; WBS, Warner-Bratzler shear force; TBARS, thiobarbituric acid reactive substances; MDA, malondialdehyde.

${ }^{a-c}$ Means within a row without a common superscript letter differ $(p<0.05)$. 
Buffalo meat from the silage maize diet showed the highest $L^{*}$ value and the lowest $a^{*}$ value compared with the other groups ( $\mathrm{p}<0.001$ for both), while the yellowness index was highest in the MS group (14.53). The other two groups did not show significant differences from each other.

WBS on raw meat reported a lower value in the MS group than the others $(\mathrm{p}=0.013)$, and no difference was found in WBS on cooked meat.

Buffaloes fed MS and polyphite hay showed a higher fat percentage $(p<0.001)$, while no significant differences were reported for the other proximate compounds.

Total collagen was higher in the PA and PH groups than in the animals fed MS ( $p=0.004)$, while insoluble collagen was not significant.

The oxidation parameter, TBARS, was higher in the MS group than in the PA group, 0.16 vs $0.11 \mathrm{mg} \mathrm{MDA} / \mathrm{kg}$ at 7 days. As we expected, TBARS increased from 7 to 14 days of storage time, particularly in the MS group, which had the highest value $(\mathrm{p}<0.001)$.

The fatty acid profile (Table 5 ) showed the effects of different diets. For SFAs, our data reported significant differences only for myristic acid (C14:0) and palmitic acid (C16:0), with the highest value for the MS group ( $\mathrm{p}<0.05$ for both fatty acids), while for MUFAs, the C16:1 and C18:1 cis-11 were lower in the same group. The greatest differences were found for some PUFAs and n-3 fatty acids; in fact, PA feed increased the intake of polyunsaturated n-3 fatty acids (Table 1).

In particular, the PA group reported a higher value than the MS group in CLAcis- 9 trans- 11 (0.35\% vs $0.22 \%)$, long chain PUFAs (LC PUFA n-3) such as eicosapentaenoic acid (C20:5 n-3), docosapentaenoic acid (C22:5 n-3), and docosahexaenoic acid (C22:6n-3) and consequently showed the lowest $\mathrm{n}-6 / \mathrm{n}-3$ ratio and atherogenic and TI $(\mathrm{p}=0.003$ and $\mathrm{p}=0.006$, respectively).

PCA was used to identify a classification criterion for meat samples, using the feeding system as a grouping variable. PCA 1 and PCA 2 explained $82 \%$ of the variability and clearly separated the three groups (Figure 2). Using only the significant qualitative parameters indicated in the tables, 0.89 $\mathrm{R}^{2}$ and 0.21 RMSE were obtained. The loading plot (Figure 3) clearly showed the importance of fatty acids to determine the qualitative differences of meat for SFA, PUFA fatty acids and n-6/n-3 ratio. For physical parameters, colour (lightness and yellowness) and cooking loss were important to separate the three groups. The PA group was in opposition to the $n-6 /$ $\mathrm{n}-3$ ratio, SFA and colour parameters $\left(\mathrm{L}^{*}\right.$ and $\left.\mathrm{b}^{*}\right)$ because it showed redder and leaner meat, while the MS group, which showed lighter and fatter meat, was in the opposite position with respect to $\mathrm{PA}$, where SFA, $\mathrm{L}^{*}$, and $\mathrm{b}^{*}$ absorb major variability. The PH group was in the intermediate position, characterized by PUFAs, in the opposite position of cooking
Table 5. Fatty acids composition of longissimus thoracis muscle (\% of total fatty acid methyl ester)

\begin{tabular}{|c|c|c|c|c|c|}
\hline$\%$ & MS & $\mathrm{PH}$ & PA & RMSE & p-value \\
\hline C12:0 & 0.09 & 0.08 & 0.06 & 0.03 & 0.337 \\
\hline C14:0 & $1.15^{\mathrm{a}}$ & $0.90^{b}$ & $0.76^{b}$ & 0.15 & 0.003 \\
\hline C15:0 & 0.21 & 0.23 & 0.23 & 0.04 & 0.213 \\
\hline C16:0 & $21.80^{\mathrm{a}}$ & $19.97^{b}$ & $19.50^{\mathrm{b}}$ & 1.04 & 0.050 \\
\hline C16:1 & $0.72^{b}$ & $1.13^{\mathrm{a}}$ & $1.11^{\mathrm{a}}$ & 0.25 & 0.002 \\
\hline C17:0 & 0.91 & 1.01 & 1.01 & 0.11 & 0.096 \\
\hline $\mathrm{C} 17: 1$ & 0.43 & 0.42 & 0.46 & 0.07 & 0.486 \\
\hline C18:0 & 20.72 & 20.84 & 19.83 & 2.10 & 0.366 \\
\hline C18:1 trans-9 & 0.08 & 0.11 & 0.12 & 0.06 & 0.214 \\
\hline C18:1 cis-9 & 33.42 & 34.01 & 34.76 & 2.56 & 0.892 \\
\hline C18:1 cis-11 & $0.50^{b}$ & $0.85^{a}$ & $0.97^{\mathrm{a}}$ & 0.19 & $<0.001$ \\
\hline C18:2n-6 & 13.18 & 12.84 & 12.99 & 2.57 & 0.983 \\
\hline CLA cis-9trans-11 & $0.22^{c}$ & $0.29^{b}$ & $0.35^{\mathrm{a}}$ & 0.05 & $<0.001$ \\
\hline C18:3 n-3 & $0.77^{c}$ & $1.07^{\mathrm{b}}$ & $1.32^{a}$ & 0.31 & $<0.011$ \\
\hline C18:3 n-6 & 0.20 & 0.19 & 0.18 & 0.07 & 0.827 \\
\hline C20:0 & 0.13 & 0.17 & 0.16 & 0.04 & 0.064 \\
\hline C20:3 n-6 & 1.02 & 1.08 & 1.21 & 0.35 & 0.067 \\
\hline C20:4 n-6 & 3.17 & 2.76 & 2.68 & 0.90 & 0.390 \\
\hline C20:5 n-3 & $0.22^{c}$ & $0.18^{b}$ & $0.57^{\mathrm{a}}$ & 0.12 & 0.004 \\
\hline C22:4 n-6 & 0.52 & 0.59 & 0.55 & 0.13 & 0.609 \\
\hline$C 22: 5 n-3$ & $0.49^{b}$ & $0.85^{a}$ & $1.02^{a}$ & 0.26 & 0.006 \\
\hline$C 22: 6 n-3$ & $0.05^{b}$ & $0.13^{a}$ & $0.16^{a}$ & 0.09 & 0.021 \\
\hline SFA & 45.01 & 43.20 & 41.55 & 2.23 & 0.064 \\
\hline MUFA & 35.15 & 36.52 & 37.42 & 3.74 & 0.636 \\
\hline PUFA & 18.84 & 20.28 & 21.03 & 3.86 & 0.761 \\
\hline PUFA/SFA & 0.42 & 0.47 & 0.51 & 0.11 & 0.479 \\
\hline PUFA n-6 & 19.09 & 17.46 & 17.61 & 3.47 & 0.517 \\
\hline PUFA n-3 & $1.53^{c}$ & $2.53^{b}$ & $3.07^{a}$ & 0.58 & 0.003 \\
\hline$n-6 / n-3$ & $12.47^{\mathrm{a}}$ & $6.90^{\mathrm{b}}$ & $5.74^{c}$ & 1.37 & $<0.001$ \\
\hline $\mathrm{Al}^{1)}$ & $0.48^{\mathrm{a}}$ & $0.42^{\mathrm{ab}}$ & $0.39^{b}$ & 0.04 & 0.003 \\
\hline $\mathrm{Tl}^{2)}$ & $1.32^{\mathrm{a}}$ & $1.20^{\mathrm{ab}}$ & $1.09^{b}$ & 0.15 & 0.006 \\
\hline
\end{tabular}

MS, maize silage; $\mathrm{PH}$, polyphite meadow hay; PA, pastures; RMSE, root mean standard error; SFA, saturated fatty acids; MUFA, mono unsaturated fatty acid; PUFA, poly unsaturated fatty acid.

1) $\mathrm{Al}$, atherogenic index $=[\mathrm{C} 12: 0+(4 \times \mathrm{C} 14: 0)+\mathrm{C} 16: 0] /[(\Sigma \mathrm{PUFA})+($ MUFA $)]$

2) $\mathrm{TI}$, thrombogenic index $=[\mathrm{C} 14: 0+\mathrm{C} 16: 0+\mathrm{C} 18: 0] /[(0.5 \times \Sigma \mathrm{MUFA})+(0.5 \times \mathrm{n} 6)$ $+(3 \times n 3)+(n 3 / n 6)]$

${ }^{a-c}$ Means within a row without a common superscript letter differ $(p<0.05)$

loss.

\section{DISCUSSION}

Feeding systems influenced productive performance and meat quality, as reported by several authors reviewed by Muir et al [24]. As we expected, major differences were found between the buffaloes fed silage maize and the PA group, which were the two opposite livestock management practices, while the animals fed polyphite meadow hay were in the intermediate position.

Grazing caused lower ADG than the other groups due to both energy consumption for major activities linked to grazing and a ration richer in fibre; this last factor also affects the 


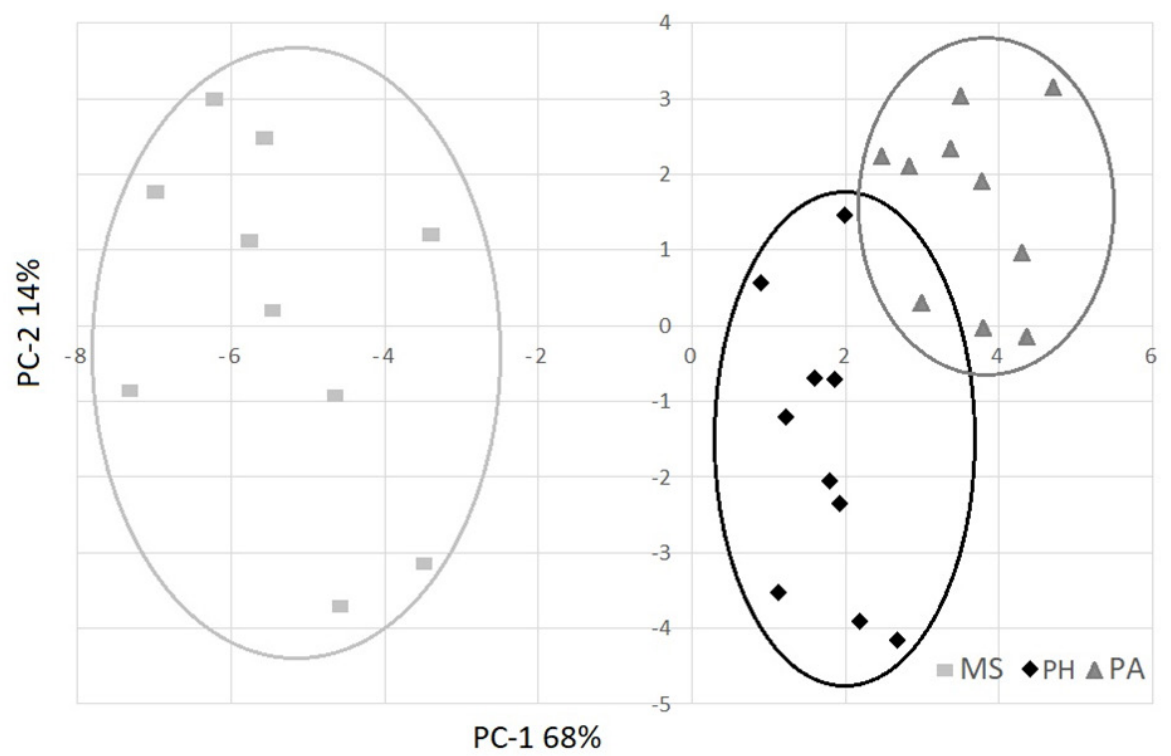

Figure 2. Scores on two principal components for meat samples produced from buffaloes fed with maize silage (MS), polyphite meadow hay $(\mathrm{PH})$ and pasture $(\mathrm{PA})$.

content of the gastroenteric apparatus and therefore the carcass yield with about $-28 \mathrm{~kg}$ for carcass weight than buffalo fed MS, despite slaughter at a similar live weight, which consequently affects the carcass yield $[9,25]$. However, Lambertz et al [9] found a difference of $200 \mathrm{~g}$ in ADG in animals bred with only PA feeding relative to those fed in pens; this more marked difference was probably due to the absence of concentrate integration in grazing animals. As reported by Lapitan et al [7], the effect of poorer feeding on ADG was less distinct in buffalo than in beef due to its greater ability to utilize roughage. The conformation and adiposity scores among the intensively reared animals ( $\mathrm{MS}$ and $\mathrm{PH}$ ) showed the

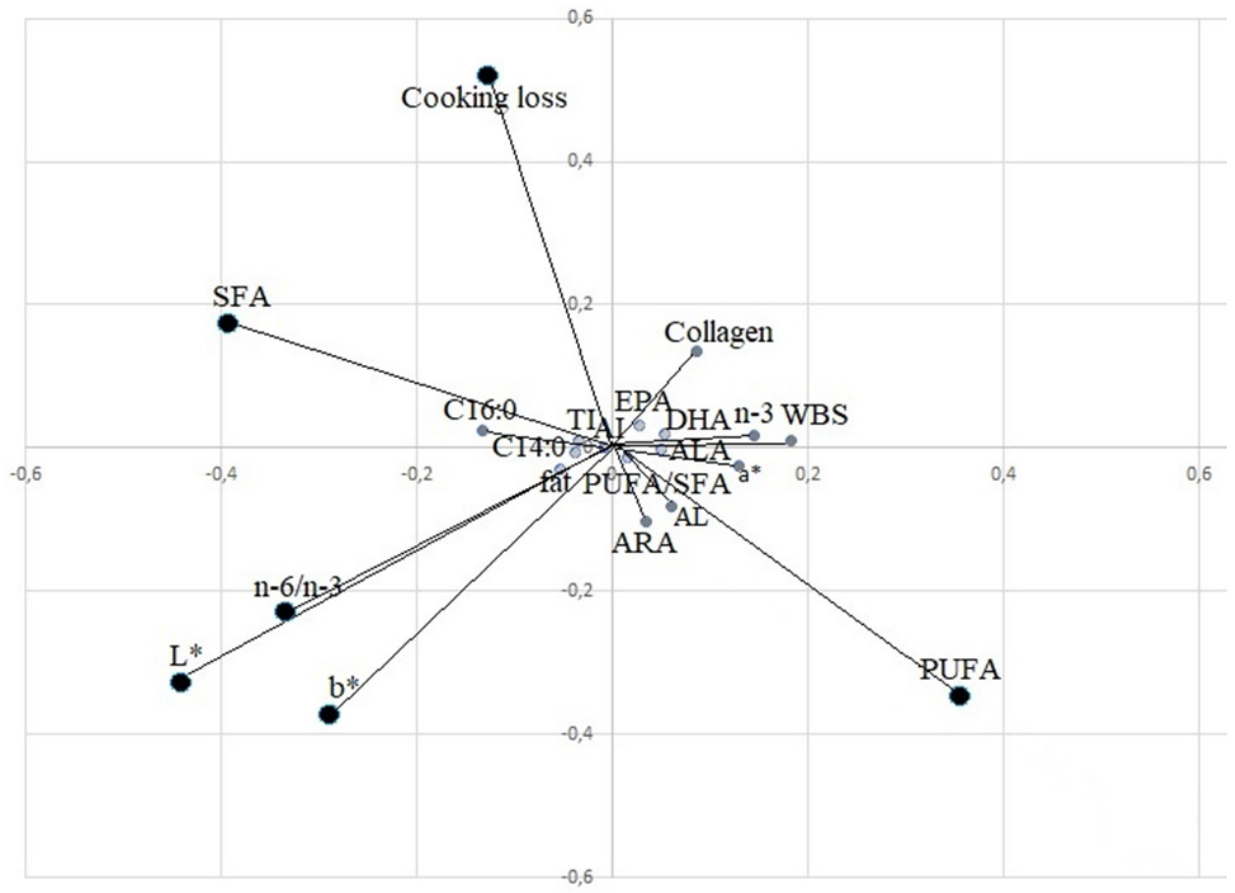

Figure 3. Principal component analysis (PCA) loading plot of the meat variables that absorbed the major variability on the first two PCs. MUFA, mono unsaturated fatty acid; SFA, saturated fatty acids; PUFA, poly unsaturated fatty acid, ARA, arachidonic acid; ALA, a-linolenic acid; AL, linoleic acid; EPA, eicosapentaenoic acid; DHA, docosahexaenoic acid; WBS, warner bratzel shear force; Al, atherogenic index; TI, thrombogenic index. 
same trend reported by Cifuni et al [1] in animals older than 16 months.

Buffaloes fed roughage or by grazing showed significantly leaner carcasses $[1,8]$ for both cattle and buffalo, confirming that diet influenced fat deposition.

Anatomical regions expressed in $\mathrm{kg}$ followed the carcass weight trend, with the higher weight in MS carcasses for all anatomical regions considered, reaching a difference of 9.5 $\mathrm{kg}$ compared to animals raised on PA. The anatomical regions included in the percentage of total carcass weight (Table 3) were similar to those reported by Lapitan et al [7] and Lambertz et al [9], which showed a significantly lower incidence in briskets between animals fed on only PA compared to those who received integrated feeding with concentrate. MS feeding significantly increased the incidence of the abdominal region, the area of choice for fat deposition, because the animals that received high energy intake, even if young, were fattened.

Meat quality (Table 4) was significantly affected by the feeding system. High $\mathrm{pH}$ in meat from animals fed on PA was reported by several authors $[10,13]$. Animals fed a richer diet generally accumulate more glycogen in muscles, which, after slaughter, due to the transformation of glycogen into lactic acid, contributes to a decrease in $\mathrm{pH}$ during ageing [11]. Furthermore, a greater adipose panicle in the carcass determines lower heat exchange during ageing, which can cause a slower decrease in temperature, affecting the $\mathrm{pH}$ [6]. Additionally, the difference in cooking loss could be due to the higher fat content in the MS group that was partly lost in the cooking liquid; in fact, meat containing a high percentage of fat results in greater cooking loss than lean meat [1].

The MS group was lighter than the others, in fact showed a higher $L^{*}$ colour values than the other groups $(p<0.001)$, probably due to the greater amount of fat and to lower $\mathrm{pH}$, factors that can be considered a contributing cause of the same phenomena; in fact, the high incidence of subcutaneous fat causes a slower cooling rate of carcasses, corresponding to a faster $\mathrm{pH}$ decrease [11] [4,21].

Colour is an important quality parameter that guides the consumer's choice, and if the $\Delta \mathrm{E}^{*}$ value exceeds the threshold of just noticeable difference (JND $=2.3$ ), it means that differences in colour are perceived by the human eye (CIE, 1976). The MS group indeed showed evident differences between animals fed on hay $\left(\Delta \mathrm{E}^{\star}=5.3\right)$ and grazing $\left(\Delta \mathrm{E}^{\star}=8.7\right)$; between these two groups, the grazing animals tended to show a darker colour, although not significantly, with non-perceptible colour differences $\left(\Delta \mathrm{E}^{\star}=1.4\right)$. In contrast, Huuskonen et al [26] did not detect significant differences in the meat colour of cattle finished on PA compared with those finished on MS [24], probably because no differences in fat score were reported. Furthermore, Marrone et al [8] found in meat from buffaloes fattening with rye grass higher values of $\mathrm{a}^{*}$, $\mathrm{b}^{\star}$, and lower lightness compared to concentrate fattening group.

Tenderness was considered by consumers to be the most important component of meat quality. In cooked meat, the diets did not affect the WBS parameter, as reported by several authors $[1,8,9]$, but probably due to fat, the lowest value of WBS in raw meat was reported in the MS group ( $\mathrm{p}=$ 0.0134 ), and a negative correlation between fat and shear force, even if limited, was highlighted by Fiem et al [27], who also described a negative correlation between shear force and lightness. Similar data between concentrate-fed and grass-fed animals were reported by Nuernberg et al [13] in beef. Even the greater presence of total collagen could influence the WBS value [20]; in fact, animals with a lower quantity of collagen (MS group) had a meat that was tender, and the differences were erased considering the percentage of insolubility, which partly explains the lack of a significant difference between groups in WBS on cooked meat [20]. Some authors associated the increase in collagen with lower daily weight gain, low protein turnover and constant movement of animals during grazing [28]. The proximate composition of meat once again underlines the limited accumulation of fat in grazing animals $[9,10,25]$.

Lipid oxidation showed the expected trend; in fact, buffaloes fed by grazing showed a lower TBARS than MS, but the difference was more considerable at 14 days of ageing, as reported by Nuernberg et al [13] at 5 and 10 days for cattle fed on grass or concentrate. Most likely, the animals on PA retained more vitamin E, polyphenols and carotenoids with a high antioxidant effect [13,29]. Lipid oxidation increased with ageing time because of a normal degradation process [30], but even if buffalo meat had a high iron concentration [4], the oxidation process was not particularly high compared to the value reported in bovines by Nuernberg et al [13].

Several authors considered the importance of grass feeding to improve the CLA, n-3 and n- 6 fatty acids $[10,13,14$, 25,26]. CLA cis- 9 trans- 11 has important nutraceutical effects on human health. A switch from a concentrate-based diet to PA has been shown to increase CLA content $[13,14]$; in fact, CLA cis-9 trans-11 in our data was higher in PA than MS $(\mathrm{p}<0.001)$. Grazing and green hay improved the trans vaccenic acid content, an important fatty acid for de novo synthesis of CLA, as reported by Daley et al [14], who also underlined in his review that the rumen in animals fed on PA or green forage during ruminal fermentation shows an optimal $\mathrm{pH}$ value for growing Butyrivibrio fibrisolvents, an important rumen bacteria for microbial biohydrogenation. Regarding $n-3$ fatty acids and the $n-6 / n-3$ ratio, we found that the PA group had the highest values for $n-3$ and the best $n-6 / n-3$ ratio relative to the MS group, as well as high linolenic fatty acid content compared to LCPUFA n-3. The PH group had an intermedi- 
ate n-3 fatty acid content and n-6/n-3 ratio, while LCPUFA $\mathrm{n}-3$ showed a similar value compared to the PA group.

A decrease in the n-6/n-3 PUFA ratio as well as an increase in the PUFA/SFA was described by Leheska et al [10] for beef with the inclusion of grass in the diet. In our data, the two ratios considered for PA meat were in line with the recommendations from the World Health Organization $(>0.45$ for PUFA/SFA ratio and $<5$ for $n-6 / n-3)$. In addition, the beneficial effect linked to the presence of grass in the diet produces lower adipose accumulation, which results in significantly lower values of myristic acid and palmitic acid, thus significantly lowering the atherogenic and TI compared to MS, confirming the results of Giordano et al [2] regarding the beneficial effects of buffalo meat in limiting the onset of cardiovascular disease [3]. Additionally, other studies [13,26] found lower values for these fatty acids in grass-fed and meadow hay-fed animals. For MUFA fatty acids, only palmitoleic (C16:1) and octadecenoic acid (C18:1 cis-11) showed significant differences, having the lowest incidence for meat of the MS group, as referred to by Giuffrida-Mendoza et al [3]. The incidence of MUFA declines in muscle as fat deposition increases. MUFA fatty acids are positioned under intermediate conditions for human health considering their protective effect against lipid oxidation by PUFAs. The $n-6$ fatty acids that represent substrates for pro-inflammatory eicosanoids did not show significant differences between the experimental groups except for arachidonic acid (C20:4 n-6), which was abundant in animals fed corn silage [10]. These changes in fatty acid composition (particularly for LCPUFA n-3 and CLA) linked to PA feeding of buffalo were favourable regarding current human dietary guidelines [10].

The PCA confirms in the results obtained with the single variables, in particular from the analysis of the scores, the distance of MS with respect to the other two groups appears clear, and the overlap in part shows the beneficial effects of grazing and diet on nutritional values, while the MS group stands out in a positive manner for its light colour.

The PUFA n-3, CLA cis- 9 trans- 11 , and n- $6 / n-3$ values suggest that buffalo meat breeding on PA or good meadow hay is potentially more beneficial for nutrition or human health. These two feeding systems could respond to many consumer needs, though they did not present excellent production performance.

\section{CONFLICT OF INTEREST}

We certify that there is no conflict of interest with any financial organization regarding the material discussed in the manuscript.

\section{FUNDING}

The authors received no financial support for this article.

\section{REFERENCES}

1. Cifuni GF, Contò M, Amici A, Failla S. Physical and nutritional properties of buffalo meat finished on hay or maize silagebased diets. Anim Sci J 2014;85:405-10. https://doi.org/10. 1111/asj.12152

2. Giordano G, Guarini P, Ferrari P, Biondi-Zoccai G, Schiavone B, Giordano A. Beneficial impact on cardiovascular risk profile of water buffalo meat consumption. Eur J Clin Nutr 2010;64:1000-6. https://doi.org/10.1038/ejcn.2010.108

3. Giuffrida-Mendoza M, Arenas de Moreno L, Huerta-Leidenz $\mathrm{N}$, et al. Cholesterol and fatty acid composition of longissimus thoracis from water buffalo (Bubalus bubalis) and Brahmaninfluenced cattle raised under savannah conditions. Meat Sci 2015;106:44-9. https://doi.org/10.1016/j.meatsci.2015. 03.024

4. Tamburrano A, Tavazzi B, Callà CAM, et al. Biochemical and nutritional characteristics of buffalo meat and potential implications on human health for a personalized nutrition. Ital J Food Saf 2019;8:8317. https://doi.org/10.4081/ijfs.2019. 8317

5. Spanghero M, Gracco L, Valusso R, Piasenter E. In vivo performance, slaughtering traits and meat quality of bovine (Italian Simmental) and buffalo (Italian Mediterranean) bulls. Livest Prod Sci 2004;91:129-41. https://doi.org/10. 1016/j.livprodsci.2004.07.013

6. Neath KE, Del Barrio AN, Katsube O, et al. Difference in tenderness and $\mathrm{pH}$ decline between water buffalo meat and beef during postmortem aging. Meat Sci 2007;75:499-505. https://doi.org/10.1016/j.meatsci.2006.08.016

7. Lapitan RM, Del Barrio AN, Katsube O, et al. Comparison of fattening performance in Brahman grade cattle (Bos indicus) and crossbred water buffalo (Bubalus bubalis) fed on high roughage diet. Anim Sci J 2008;79:76-82. https:// doi.org/10.1111/j.1740-0929.2007.00500.x

8. Marrone R, Salzano A, Di Francia A, et al. Effects of feeding and maturation system on qualitative characteristics of buffalo meat (Bubalus bubalis). Animal 2020;10:899. https://doi.org/ 10.3390/ani10050899

9. Lambertz C, Panprasert P, Holtz W, et al. Carcass characteristics and meat quality of swamp buffaloes (Bubalus bubalis) fattened at different feeding intensities. Asian-Australas J Anim Sci 2014;27:551-60. https://doi.org/10.5713/ajas.2013. 13555

10.Leheska JM, Thompson LD, Howe JC, et al. Effects of conventional and grass-feeding systems on the nutrient composition of beef. J Anim Sci 2008;86:3575-85. https://doi.org/10.2527/ jas.2007-0565

11.Priolo A, Micol D, Agabriel J. Effects of grass feeding systems on ruminant meat colour and flavour. A review. Anim Res 
2001;50:185-200. https://doi.org/10.1051/animres:2001125

12.Stampa E, Schipmann-Schwarze C, Hamm U. Consumer perceptions, preferences, and behavior regarding pastureraised livestock products: a review. Food Qual Pref 2020;82: 103872. https://doi.org/10.1016/j.foodqual.2020.103872

13. Nuernberg K, Dannenberger D, Nuernberg G, et al. Effect of a grass-based and a concentrate feeding system on meat quality characteristics and fatty acid composition of longissimus muscle in different cattle breeds. Livest Prod Sci 2005;94:13747. https://doi.org/10.1016/j.livprodsci.2004.11.036

14. Daley CA, Abbott A, Doyle PS, Nader GA, Larson S. A review of fatty acid profiles and antioxidant content in grass-fed and grain-fed beef. Nutr J 2010;9:10. https://doi.org/10.1186/ 1475-2891-9-10

15. Fruet APB, Stefanello FS, Trombetta F, et al. Growth performance and carcass traits of steers finished on three different systems including legume-grass pasture and grain diets. Animal 2019;13:1552-62. https://doi.org/10.1017/S1751731 118003142

16. AOAC International. Association of Official Analytical Chemist (AOAC). Official methods of analysis of AOAC International. 16th ed. Arlington, VA, USA: AOAC International; 1995.

17.Van Soest PJ, Robertson JB, Lewis BA. Methods for dietary fiber, neutral detergent fiber, and nonstarch polysaccharides in relation to animal nutrition. J Dairy Sci 1991;74:3583-97. https://doi.org/10.3168/jds.S0022-0302(91)78551-2

18.EEC. Reg. CE n 1249/2008. Community scale for the classification of carcass of adult bovine animals. R (CEE) no.1026/91. Office for official publications of the European communities, L-2985 Luxemburg. Each class of both scales (conformation and fatness) was subdivided in 3 sub-classes (18 subclasses for conformation and 15 for fatness evaluation).

19. Honikel KO. Reference methods for the assessment of physical characteristics of meat. Meat Sci 1998;49:447-57. https:// doi.org/10.1016/S0309-1740(98)00034-5

20. Christensen M, Ertbjerg P, Failla S, et al. Relationship between collagen characteristics, lipid content and raw and cooked texture of meat from young bulls of fifteen European breeds. Meat Sci 2011;87:61-5. https://doi.org/10.1016/j.meatsci. 2010.09.003

21.Ripoll G, Albertí P, Panea B, et al. Colour variability of beef in young bulls from fifteen European breeds. Int J Food Sci Technol 2018;53:2777-85. https://doi.org/10.1111/ijfs.13890

22. Bergamo P, Fedele E, Balestrieri M, Abrescia P, Ferrara L. Measurement of malondialdehyde levels in food by highperformance liquid chromatography with fluorometric detection. J Agric Food Chem 1998;46:2171-6. https://doi. org/10.1021/jf9709919

23. Ulbricht TLV, Southgate DAT. Coronary heart disease: seven dietary factors. Lancet 1991;338:985-92. https://doi.org/10. 1016/0140-6736(91)91846-m

24. Muir PD, Deaker JM, Bown MD. Effects of forage- and grainbased feeding systems on beef quality: a review. New Zeal J Agric Res 1998;41:623-35. https://doi.org/10.1080/00288233. 1998.9513346

25.Duckett SK, Neel JPS, Lewis RM, Fonteno JP, Clapham WM. Effects of forage species or concentrate finishing on animal performance, carcass and meat quality. J Anim Sci 2013;91: 1454-67. https://doi.org/10.2527/jas.2012-5914

26. Huuskonen A, Jansson S, Honkavaara M, Tuomisto L, Kauppinen R. Performance, meat fatty acid profile and meat colour of dairy bulls finished on grazed pasture or grass silagebased diets with similar concentrate allowances. Acta Agric Scand 2010;60:104-11. https://doi.org/10.1080/09064702.20 10.491868

27. Fiems LO, De Campeneere S, De Smet S, Van de Voorde G, Vanacker JM, Boucqué ChV. Relationship between fat depots in carcasses of beef bulls and effect on meat colour and tenderness. Meat Sci 2000;56:41-7. https://doi.org/10.1016/ s0309-1740(00)00017-6

28.Silva CCG, Rego OA, Simões ERE, Rosa HJD. Consumption of high energy maize diets is associated with increased soluble collagen in muscle of Holstein bulls. Meat Sci 2010;86:7537. https://doi.org/10.1016/j.meatsci.2010.06.017

29. Cascone A, Paduano A, Battimo I, et al. Lipid oxidation in buffalo meat from animals with dietary supplementation of vitamin E. Proceedings of the 8th World Buffalo Congress, 2007 October 19-22: Caserta, Italy. Ital J Anim Sci 2007;6(Issue Sup2):1191-4. https://doi.org/10.4081/ijas.2007.s2.1191

30.Descalzo AM, Rossetti L, Sancho AM, et al. Antioxidant consumption and development of oxidation during ageing of buffalo meat produced in Argentina. Meat Sci 2008;79: 582-8. https://doi.org/10.1016/j.meatsci.2007.10.020 